Third, although recipient diagnosis overall did not differ between groups, contused lungs were transplanted in only 2 of 44 patients $(4.5 \%)$ with pulmonary arterial hypertension (PAH), compared with 57 of $650(8.8 \%)$ in the control group. Contused donor lung recipients may have been unwittingly selected, thereby avoiding patients with PAH at increased risk for developing PGD posttransplantation.

This interesting report from a well-respected and high-volume lung transplant center in Europe is the first indepth outcome study using lungs from donors who had sustained significant chest trauma. These results may guide other lung transplant centers in considering whether to accept contused lungs from selected donors more frequently (Figure 2). This policy may further enlarge the lung donor pool, thereby decreasing total waiting time and waiting list mortality.

We should be grateful to the Vienna Lung Transplant group for bringing these types of lung donors to our attention and demonstrating that contusion per se is not an absolute exclusion criterion for lung donation. When carefully selected, bruised donor lungs can still support recipients' life immediately after transplantation, with no impact on early or long-term outcome.

\section{References}

1. Organ Procurement and Transplantation Network. National data. Accessed November 29, 2020. Available at: https://optn.transplant.hrsa.gov/data/viewdata-reports/national-data/

2. Van Raemdonck D, Neyrinck A, Verleden GM, Dupont L, Coosemans W, Decaluwé H, et al. Lung donor selection and management. Proc Am Thorac Soc. 2009;6:28-38.

3. Meers C, Van Raemdonck D, Verleden GM, Coosemans W, Decaluwé H, De Leyn P, et al. The number of lung transplants can be safely doubled using extended criteria donors; a single-center review. Transplant Int. 2010;23:628-35.

4. Martens A, Neyrinck A, Van Raemdonck D. Accepting donor lungs for transplant: let Lisa and Bob finish the job! Eur J Cardiothorac Surg. 2016;50:832-3.

5. Schwarz S, Rahimi N, Kifjak D, Frommlet F, Benazzo A, Jaksch P, et al. Lungs from polytrauma donors with significant chest trauma can be safely used for transplantation. J Thorac Cardiovasc Surg. 2022;163:1719-31.e2.

6. Oto T, Levvey BJ, Whitford H, Griffiths AP, Kotsimbos T, Williams TJ, et al. Feasibility and utility of a lung donor score: correlation with early post-transplant outcomes. Ann Thorac Surg. 2007;83:257-63.

7. Smits JM, van der Bij W, Van Raemdonck D, de Vries E, Rahmel A, Laufer G, et al. Defining an extended criteria donor lung: an empirical approach based on the Eurotransplant experience. Transpl Int. 2011;24:393-400.

8. Loor G, Radosevich DM, Kelly RF, Cich I, Grabowski TS, Lyon C, et al. The University of Minnesota donor lung quality index: a consensus-based scoring application improves donor lung use. Ann Thorac Surg. 2016;102:1156-65.

9. Ehrsam JP, Held U, Opitz I, Inci I. A new lung donor score to predict short and long-term survival in lung transplantation. J Thorac Dis. 2020;12:5485-94.

10. Schwarz S, Rahimi N, Kifjak D, Muckenhuber M, Watzenböck M, Benazzo A, et al Comparison of donor scores in bilateral lung transplantation-a large single-center analysis. Am J Transplant. November 19, 2020 [Epub ahead of print].

\title{
Commentary: Bruised and battered, but not broken - use of lung allografts from donors with chest trauma
}

\author{
Samuel J. Kesseli, MD, ${ }^{a}$ Samantha E. Halpern, BA, ${ }^{\mathrm{b}}$ \\ and Mathew G. Hartwig, $\mathrm{MD}^{\mathrm{c}}$
}

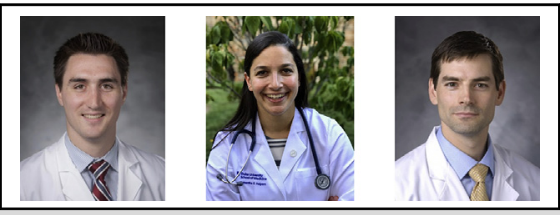

Samuel J. Kesseli, MD (left), Samantha E. Halpern, BA (middle), and Mathew G. Hartwig, MD (right)

\section{CENTRAL MESSAGE \\ Investigation by the Vienna Lung Transplant Group demonstrates selected lungs with traumatic contusion can be safely utilized with comparable outcomes to grafts from donors without trauma.}

Eligible donors with traumatic injuries comprise more than one-third of the overall deceased donor pool, tend to be younger, and yield high-quality grafts. ${ }^{1}$ With respect to lung grafts, some consider polytrauma donors high-risk and significant practice variability exists in organ acceptance from this donor pool. Current guidelines recommend
Fem the Department of Surgery and Division of Cardiovascular and Thoracic SurDurham, NC

isclosures: Dr Hartwig consults for Bridge to Life, Paragonix, Medtronic, Biointerest.

The Journal policy requires editors and reviewers to disclose conflicts of interest and to decline handling or reviewing manuscripts for which they may have a conflict of interest. The editors and reviewers of this article have no conflicts of interest. publication Nov 19, 2020; available ahead of print Dec 1, 2020.

Medical Center, 2301 Erwin Rd, Durham, NC 27710 (E-mail: Samuel.Kesseli@ Duke.edu)

J Thorac Cardiovasc Surg 2022;163:1735-6

$0022-5223 / \$ 36.00$

Copyright $(2020$ by The American Association for Thoracic Surgery

https://doi.org/10.1016/j.jtcvs.2020.11.093 
declining lung grafts with "severe trauma not appreciated on [computed tomography]"2; however, objective guidelines that specifically define severe trauma are lacking.

Schwarz and colleagues ${ }^{3}$ of the Vienna Lung Transplant Group report a retrospective single-center analysis of 1152 donor lungs; of these, 118 came from polytrauma donors and 44 had radiologic evidence of contusion before proceeding to transplant. The authors found similar rates of graft dysfunction, ventilation time, freedom from rejection, 1-year survival, and 5-year survival among recipients of grafts from donors with traumatic contusion and those without trauma. Notably, donors with trauma but without contusion had superior graft survival compared with the nontrauma controls. This might suggest that in terms of overall graft survival, the presence of contusion is counterbalanced by the superior quality of grafts from younger, less-comorbid-trauma populations.

The authors should be commended for their analysis of this specific donor population. However, it remains uncertain how these findings may influence the donor pool. In the United States, lungs are transplanted from about $22.5 \%$ of eligible donors. ${ }^{4}$ Among cases in which lungs were not recovered from eligible donors (63.1\% of all donors in 2018), trauma to organ accounted for only 112 out of 6767 refusals $(0.02 \%)$ and ruled out after evaluation in the operating room accounted for 399 of $6767(0.06 \%)$. Among grafts discarded after recovery, trauma was cited as the reason for discard in only 5 of 135 grafts $(0.04 \%))^{4}$ The most common reason for either refusal or discard was poor organ function, typically defined by the arterial partial pressure of oxygen divided by the inspired oxygen concentration (also known as the $\mathrm{P} / \mathrm{F}$ ratio) (2312 out of 6767 or $34 \%$ of those not recovered). Although the authors have clearly demonstrated value and safety in utilization of selected donors with lung contusion (about $3.8 \%$ of all donors in their cohort), one must acknowledge that utilizing these donors in some countries may not expand the donor pool to the same degree as it did in their series. Unfortunately, current data collection for donor turndown by the Scientific Registry of Transplant Recipients remains inadequate for reliable analysis to aid in understanding the reasons behind donor organ nonuse, so the true influence remains unknown.

Most importantly, given that objective measurements of severity of contusions are not available to the authors and 10 of 16 trauma-donor lungs declined in their series had contusions, the question remains: How much contusion is too much? A considerable limitation of this study is that the degree of contusion is not objectively quantified, and therefore the community is left only with the selection bias among the donors with contusion who were included. Although it is reassuring to know that their current practice of selectively using polytrauma donors with lung contusions provides comparable outcomes, subsequent investigation of this topic using quantitative computed tomography measurements of contusion will be valuable in answering this question with more granularity. Ultimately, although battered and bruised, this study confirms that contused lungs with good function in the donor are likely to be good lungs in the recipient as well.

\section{References}

1. Ackerman A, Clark D, Lipinska J, Chung B, Whiting J. Organ donation after trauma: a 30-year review. J Trauma Acute Care Surg. 2019;87:130-3.

2. Copeland H, Hayanga JWA, Neyrinck A, MacDonald P, Dellgren G, Bertolotti A, et al. Donor heart and lung procurement: a consensus statement. J Heart Lung Transplant. 2020;39:501-17.

3. Schwarz S, Rahimi N, Kifjak D, Frommlet F, Benazzo A, Jaksch P, et al. Lungs from polytrauma donors with significant chest trauma can be safely used for transplantation. J Thorac Cardiovasc Surg. 2022;163:1719-31.e2.

4. Israni AK, Zaun D, Rosendale JD, Schaffhausen C, Snyder JJ, Kasiske BL. OPTN/ SRTR 2018 annual data report: deceased organ donation. Am J Transplant. 2018; 18(Suppl 1):434-63. 